\title{
UNIVERSITYOF
}

FORWARD

THINKING

WESTMINSTER用

WestminsterResearch

http://www.westminster.ac.uk/westminsterresearch

Theranostic Fibers for Simultaneous Imaging and Drug Delivery

Bligh, S.W.A., Williams, G.R., Yu, D.G., Jin, M. and Geraldes, C.

This is an author's accepted manuscript of an article published in Molecular Pharmaceutics, vol. 13 (7), pp. 2457-2465, 2016. The final definitive version is available online at:

https://dx.doi.org/10.1021/acs.molpharmaceut.6b00197

The WestminsterResearch online digital archive at the University of Westminster aims to make the research output of the University available to a wider audience. Copyright and Moral Rights remain with the authors and/or copyright owners.

Whilst further distribution of specific materials from within this archive is forbidden, you may freely distribute the URL of WestminsterResearch: ((http://westminsterresearch.wmin.ac.uk/)).

In case of abuse or copyright appearing without permission e-mail repository@westminster.ac.uk 


\section{Theranostic fibers for simultaneous imaging and drug delivery}

Miao Jin, ${ }^{\dagger}$ Deng-Guang Yu, ${ }^{,{ }^{\ddagger}}$ Carlos F. G. C. Geraldes, ${ }^{\S}$ Gareth R. Williams, ${ }^{*}{ }^{\dagger}$ S. W. Annie Bligh*,ll

+ UCL School of Pharmacy, University College London, 29-39 Brunswick Square, London, WC1N 1AX, UK.

‡ School of Materials Science \& Engineering, University of Shanghai for Science and Technology, Shanghai 200093, China.

$\S$ Department of Life Sciences and Coimbra Chemistry Center - CQC, Faculty of Science and Technology, University of Coimbra, 3000-393 Coimbra, Portugal

" Department of Life Sciences, Faculty of Science and Technology, University of Westminster, 115 New Cavendish Street, London, W1W 6UW, UK.

* Authors for correspondence. Tel: +86 2155270632 (DGY); +44 (0) 2077535868 (GRW); +44 (0) 2079115038 (SWAB). Email: ydg017@usst.edu.cn (DGY); g.williams@ucl.ac.uk (GRW); a.bligh@westminster.ac.uk (SWAB). 


\title{
Graphical abstract:
}

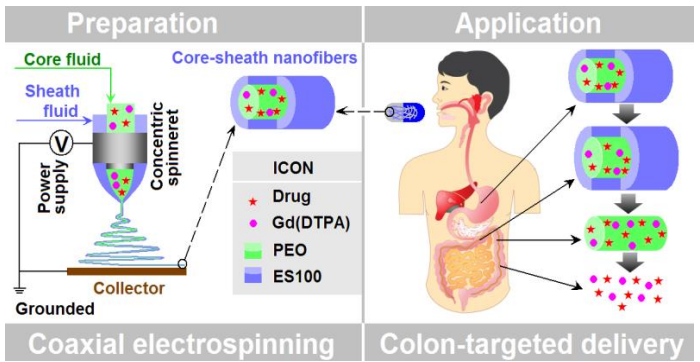

\begin{abstract}
:
New methods for creating theranostic systems with simultaneous encapsulation of therapeutic, diagnostic and targeting agents are much sought after. This work reports for the first time the use of coaxial electrospinning to prepare such systems in the form of core-shell fibers. Eudragit S100 was used to form the shell of the fibers, while the core comprised polyethylene oxide loaded with the magnetic resonance contrast agent Gd(DTPA) (Gd(III) diethylenetriaminepentaacetate hydrate) and indomethacin as a model therapeutic agent. The fibers had linear cylindrical morphologies with clear core-shell structures, as demonstrated by electron microscopy. X-ray diffraction and differential scanning calorimetry proved that both indomethacin and Gd(DTPA) were present in the fibers in the amorphous physical form. This is thought to be a result of intermolecular interactions between the different components, the presence of which was suggested by IR spectroscopy. In vitro dissolution tests indicated that the fibers could provide targeted release of the active ingredients through a combined mechanism of erosion and diffusion. The proton relaxivities for Gd(DTPA) released from the fibers into tris buffer increased $\left(r_{1}=5.03-10.13 \mathrm{~s}^{-1} \mathrm{mM}^{-1} ; \quad r_{2}=8.28-14.96 \mathrm{~s}^{-1} \mathrm{mM}^{-1}\right)$ compared with fresh Gd(DTPA) $\left(r_{1}=4.37 \mathrm{~s}^{-1} \mathrm{mM}^{-1}\right.$ and $\left.r_{2}=4.85 \mathrm{~s}^{-1} \mathrm{mM}^{-1}\right)$, proving that electrospinning has not diminished the contrast properties of the complex. The new systems reported herein thus offer a new platform for delivering therapeutic and imaging agents simultaneously to the colon.
\end{abstract}

Keywords: theranostics; image-guided drug delivery; core-shell fibers; multifunctionality; coaxial electrospinning 


\section{Introduction}

In current medicine, disease (particularly tumor) detection and therapy are largely performed separately. However, it can be much more effective to combine molecular diagnosis and therapy, performing both simultaneously in an approach known as theranostics. ${ }^{1}$ This has shown great potential in molecular diagnosis, molecular therapy, imaging-guided drug delivery and treatment monitoring. It can help to ensure effective drug delivery through the noninvasive assessment of biodistribution, the optimization of strategies for triggered drug release, and real-time monitoring of therapeutic responses. ${ }^{1}$ It can not only increase drug efficacy and safety, but can also eliminate the unnecessary treatment of patients for whom a particular therapy is not appropriate, resulting in significant cost savings for healthcare systems. ${ }^{2}$

An effective way to develop a theranostic system is to incorporate both the therapeutic and the diagnostic agents simultaneously into a single product. ${ }^{3}$ These systems to date have mainly taken the form of nanoparticles for applications in treating cancer patients. ${ }^{4}$ A variety of materials, such as inorganic ${ }^{5}$ and polymeric nanoparticles, ${ }^{6}$ have been prepared carrying both a diagnostic agent and a drug to achieve magnetic resonance imaging (MRI) and therapeutic drug delivery simultaneously. However, time-consuming processes comprising multiple steps are typically required for the preparation of such multifunctional carriers, which are also very difficult to produce on a large scale. ${ }^{3,7-10} \mathrm{New}$ methods for creating nanoscale theranostic systems are thus much sought after.

Electrospinning is a popular process widely used for generating polymer-based fibers. A polymer/active ingredient solution is first prepared, and loaded into a syringe fitted with a metal needle. The solution is ejected from the syringe towards a metal collector at a controlled rate, and a high voltage applied between the two. This results in rapid evaporation of the solvent, and the formation of one-dimensional polymer fibers. Electrospinning is simple and cheap to implement, and a wide variety of functional ingredients can be easily incorporated into the polymer matrix. ${ }^{8,11,12}$ Electrospun fibers have been found to be good candidates for a wide variety of biomedical applications such as cardiovascular stents, ${ }^{13}$ wound healing, ${ }^{14}$ and the controlled release of active ingredients. ${ }^{15-17}$ Electrospun drug-loaded fibers have been broadly explored for targeted release, for improving the dissolution rate of poorly water-soluble drugs, and for encapsulating multiple functional components. ${ }^{18-20}$ The simplest process involves a single needle, and produces monolithic fibers. The more advanced coaxial process (this uses two needles and solutions, one nested inside the other) can generate core-shell fibers, with a number of concomitant advantages. The incorporation of a drug only in the core of the fibers can protect it from heat or light, or preclude release in an inappropriate $\mathrm{pH}$ medium. If the fibers are appropriately designed, core-shell drug-loaded fibers can additionally eliminate the initial burst release commonly seen with monolithic fibers, 
resulting in zero-order release materials or multiple-phase controlled release. ${ }^{21,22}$ The simultaneous release of multiple drugs is also possible, ${ }^{23,24}$ and a wider range of polymers can be processed with the coaxial approach than with single-fluid spinning. ${ }^{25}$

Given that multiple drugs can be incorporated into coaxial electrospun fibers and released into particular parts of the body, here we aimed to fabricate a series of novel theranostic systems using this process. The literature is mainly focused on theranostics for cancer treatment, but this work is focused on systems for the diagnosis and treatment of inflammatory bowel disease (IBD). Anti-inflammatory drugs are often the first step in the treatment of IBD: hence, indomethacin, a non-steroidal anti-inflammatory drug commonly used to reduce fever, pain and inflammation, was used as a model therapeutic agent. ${ }^{26}$ Core/shell fibers were prepared with Eudragit S100, a pH-sensitive polymer commonly used as a coating to avoid drug release in the stomach, as the shell polymer. ${ }^{27}$ The biocompatible polyethylene oxide (PEO), which has a particular ability to adhere strongly to the colonic mucosa, ${ }^{28}$ was selected as the core polymer. Indomethacin and the widely-used MRI contrast agent Gd(DTPA), ${ }^{3}$ were both incorporated into the core of the fibers.

This work builds on our previous research in which we successfully produced core-shell fibers loaded with Gd(DTPA) by coaxial electrospinning. ${ }^{29}$ Gd(DTPA) was found to retain its ability to act as contrast agent after electrospinning. It was also demonstrated that functional ingredients embedded in the core of the fibers can be effectively transferred to the colonic mucosa, permitting the latter to be imaged.

The experimental strategy for the production of electrospun theranostics is illustrated schematically in Figure 1. The Eudragit shell is insoluble in acidic pHs, and thus the fibers are not expected to free any of their indomethacin or Gd(DTPA) loading in the stomach. When the fibers reach the lower (and higher $\mathrm{pH}$ ) parts of the intestine the shell will dissolve, exposing the PEO core to the gastric fluids. The PEO will swell and mucoadhere to the walls of the intestine. As it does so, the Gd(DTPA) and indomethacin will be freed and will permeate the colon wall for simultaneous imaging and treatment of IBD. A family of fibers was prepared with different molecular weight PEOs and loadings of active ingredients, fully characterized, and its functional performance assessed. 


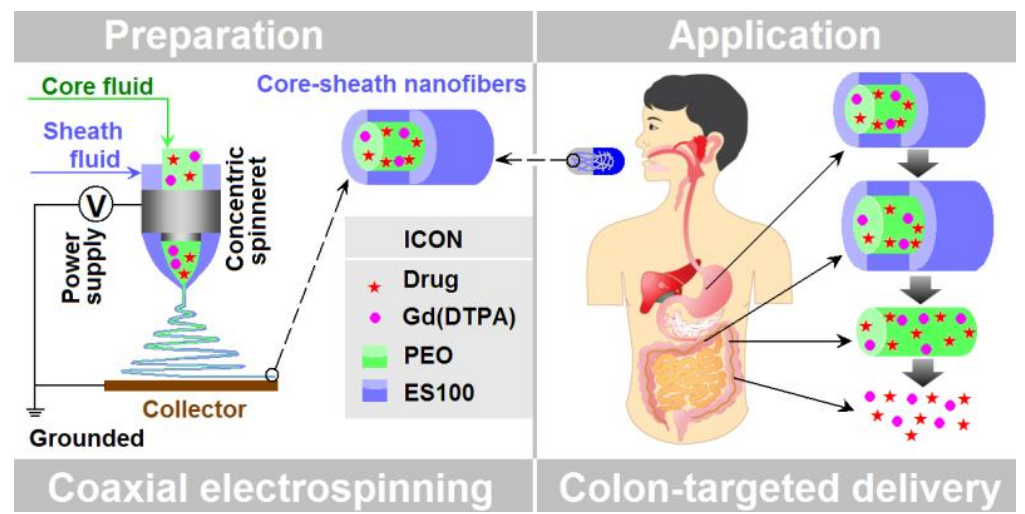

Figure 1. A schematic diagram illustrating the coaxial electrospinning process and the planned application of the resultant fibers.

\section{Experimental section}

Materials. Gadolinium(III) diethylenetriaminepentaacetate dihydrogen hydrate Gd(DTPA) and arsenazo III were purchased from Sigma-Aldrich UK. Eudragit S100 $(\mathrm{Mw}=125 \mathrm{kDa})$ was obtained from Rohm $\mathrm{GmbH}$. Polyethylene oxide samples of different molecular weights were provided by Acros Organics UK (Mw=600 kDa; PEO $0.6 \mathrm{M}$ ) or Colorcon Ltd (Mw=1000 kDa; PEO 1M). Gadolinium chloride hexahydrate, diethylenetriaminepentaacetic acid, and lanthanum oxide were supplied by Alfa Aesar UK. Indomethacin was provided by Molekula Ltd.

Anhydrous ethanol and acetone were analytical grade and procured from Fisher Scientific. Triton X100 and dimethylacetamide (DMAc) were supplied by Sigma-Aldrich. All water was deionised prior to use.

Preparation of working solutions. The shell solution consisted of $13.5 \% \mathrm{w} / \mathrm{v}$ of Eudragit S100 (ES100) in a mixture of ethanol and DMAC (8:2 v/v). A number of core solutions with varied contents of Gd(DTPA) and indomethacin with PEO 0.6M or PEO $1 \mathrm{M}$ were prepared. The solvent for the core solution was composed of water/ethanol $(3: 7 \mathrm{v} / \mathrm{v})$ with additives (acetone, $1 \% \mathrm{v} / \mathrm{v}$; Triton X100, 0.1\% v/v) included to ensure good quality fiber products. Full details are listed in Table 1. 
Table 1. The core solutions used in electrospinning

\begin{tabular}{|c|c|c|c|c|c|}
\hline Fiber & $\begin{array}{c}\text { PEO Mw } \\
\text { (kDa) }\end{array}$ & $\begin{array}{l}\text { Conc of } \\
\text { PEO } \\
(w / v \%)\end{array}$ & $\begin{array}{c}\text { Weight ratio } \\
\text { (Gd(DTPA):PEO } \\
w / w)\end{array}$ & $\begin{array}{c}\text { Weight ratio } \\
\text { (indomethacin:PEO } \\
\mathrm{w} / \mathrm{v} \text { ) }\end{array}$ & $\begin{array}{l}\text { Composition of the core } \\
\qquad / \% \mathrm{w} / \mathrm{w}\end{array}$ \\
\hline F1 & 600 & 3 & $2: 10$ & $2: 10$ & $\begin{array}{l}14.3 \% \text { Gd(DTPA); } \\
14.3 \% \text { indomethacin; } \\
71.4 \% \text { PEO }\end{array}$ \\
\hline F2 & 1000 & 2 & $1: 10$ & $1: 10$ & $\begin{array}{l}8.3 \% \text { Gd(DTPA); } \\
8.3 \% \text { indomethacin; } \\
83.4 \% \text { PEO }\end{array}$ \\
\hline F3 & 1000 & 2 & $2: 10$ & $2: 10$ & $\begin{array}{l}14.3 \% \text { Gd(DTPA); } \\
14.3 \% \text { indomethacin; } \\
71.4 \% \text { PEO }\end{array}$ \\
\hline F4 & 1000 & 2 & $3: 10$ & $3: 10$ & $\begin{array}{l}18.8 \% \text { Gd(DTPA); } \\
18.8 \% \text { indomethacin; } \\
62.5 \% \text { PEO }\end{array}$ \\
\hline
\end{tabular}

Coaxial electrospinning. A homemade concentric spinneret was used for coaxial spinning. This was prepared by inserting a small stainless steel needle (27G; outer and inner diameters of 0.42 and $0.21 \mathrm{~mm}$, respectively) into a larger needle (18G; outer and inner diameters of 1.25 and $0.84 \mathrm{~mm}$ ). A HCP 35-35000 power supply (FuG Elektronik $\mathrm{GmbH}$ ) was employed to provide high voltages. The spinning solutions were loaded into two $10 \mathrm{~mL}$ syringes and these were connected to the spinneret. Great care was taken to avoid air bubbles in the solution. An alligator clip (the positive electrode) was then attached to the concentric needle. The grounded electrode was connected to a flat collector wrapped in aluminum foil. Electrospinning was accomplished under ambient conditions $\left(22 \pm 3{ }^{\circ} \mathrm{C}\right.$ and relative humidity $30 \pm 5 \%$ ). Two syringe pumps (KDS 100, Cole-Parmer) were used to drive the working solutions. After a series of preliminary optimization experiments the applied voltage was set to $10 \mathrm{kV}$, with a spinneret-to-collector distance of $20 \mathrm{~cm}$. The shell and core fluid flow rates were fixed at 1.5 and $0.3 \mathrm{~mL} / \mathrm{h}$, respectively.

Synthesis of lanthanum(III) diethylenetriaminepentaacetate (La(DTPA)). La(DTPA) was prepared following a literature method for $\operatorname{Gd}(D T P A) .{ }^{30}$ A suspension of diethylenetriaminepentaacetic acid $(0.7868 \mathrm{~g}, 2 \mathrm{mmol})$ and lanthanum oxide (0.3261 $\mathrm{g}, 1 \mathrm{mmol}$ ) in $100 \mathrm{~mL}$ deionised water was refluxed with stirring for $2 \mathrm{~h}$, after which the solution was clear. The solvent was evaporated by rotary evaporation, after which the solid product was recovered and washed with methanol and dried under vacuum. (Found: $\mathrm{C}, 28.59 ; \mathrm{H}, 4.56 ; \mathrm{N}, 6.64 \%$. Calc'd. for $\left.\mathrm{LaC}_{14} \mathrm{H}_{20} \mathrm{O}_{10} \mathrm{~N}_{3} \cdot 2.2 \mathrm{H}_{2} \mathrm{O} \cdot \mathrm{CH}_{3} \mathrm{OH} \cdot 0.088 \mathrm{La}_{2} \mathrm{O}_{3}: \mathrm{C}, 28.62 ; \mathrm{H}, 4.55 ; \mathrm{N}, 6.67 \%\right)$.

Characterization. Scanning Electron Microscopy. The morphology of the fibers was examined using a scanning electron microscope (SEM; FEI Quanta 200 FEG ESEM instrument). Prior to examination, samples were gold sputter-coated under a 
nitrogen atmosphere to render them electrically conductive. The average fiber diameter was determined by measuring their sizes in FESEM images at more than 100 different places, using the Image J software (National Institutes of Health).

Transmission electron microscopy. Transmission electron microscopy (TEM) images of the core-shell fibers were recorded on a Philips CM 120 Bio-Twin instrument. Samples for TEM were prepared by fixing a lacey carbon-coated copper grid directly onto the collector and electrospinning onto it for several minutes.

Differential scanning calorimetry. Differential scanning calorimetry (DSC) was carried out using a Q2000 instrument (TA Instruments). Sealed samples were heated at $10{ }^{\circ} \mathrm{C} / \mathrm{min}$ from ambient temperature to $180{ }^{\circ} \mathrm{C}$ under a nitrogen gas flow of 50 $\mathrm{mL} / \mathrm{min}$.

$X$-ray diffraction. X-ray diffraction (XRD) was conducted using a Rigaku MiniFlex 600 instrument with $\mathrm{Cu} K \alpha$ radiation over the $2 \vartheta$ range $10^{\circ}$ to $35^{\circ}$, at $40 \mathrm{kV}$ and $15 \mathrm{~mA}$.

Fourier transform infrared spectroscopy. Fourier transform infrared (FTIR) spectroscopy was carried out on a Spectrum 100 spectrometer (PerkinElmer). Spectra were recorded over the range of $700 \mathrm{~cm}^{-1}$ to $1800 \mathrm{~cm}^{-1}$ at a resolution of 2 $\mathrm{cm}^{-1}$.

Proton NMR Spectroscopy. NMR spectra were recorded on a Bruker Avance 400 instrument ( ${ }^{1} \mathrm{H}$ frequency: $\left.400.1 \mathrm{MHz}\right)$. La(DTPA) $(10 \mathrm{mg})$, indomethacin $(10 \mathrm{mg})$, PEO (20 mg), physical mixtures of polymer and La(DTPA) $(10-20 \mathrm{mg}$ ), and PEO fibers (20 $\mathrm{mg}$ ) loaded with indomethacin only were all dissolved in $1 \mathrm{~mL}$ of $\mathrm{D}_{2} \mathrm{O}$ or $\mathrm{MeOD}$, and transferred into a $5 \mathrm{~mm}$-diameter NMR tube for measurement.

Gd(III) leaching studies. To monitor leaching of $\mathrm{Gd}(\mathrm{III})$ ions from the core-shell fibers, approximately $5 \mathrm{mg}$ of each fiber mat was incubated in $4 \mathrm{~mL}$ of $0.05 \mathrm{mM}$ arsenazo-III solution ( $\mathrm{pH} 7.4$ ) to permit free $\mathrm{Gd}(\mathrm{III})$ ions to form a complex with the arsenazo ligand. The resultant suspension was filtered through a $0.45 \mu \mathrm{m}$ filter. The filtrate was then analysed at $654 \mathrm{~nm}$ on a Jenway $7315 \mathrm{uv} / \mathrm{vis}$ spectrophotometer. Water and a $0.076 \mathrm{mM} \mathrm{GdCl}_{3}$ solution were used as negative and positive controls respectively.

Microwave plasma-atomic emission spectroscopy. The $\mathrm{Gd}(\mathrm{III})$ contents of the fibers were determined by microwave plasma-atomic emission spectroscopy (MP-AES; 4100 instrument, Agilent Technologies). Linear calibration curves were constructed over the range 1.56-50 ppm. Three samples ( $c a .10 \mathrm{mg}$ ) for each fiber were digested in $5 \mathrm{~cm}^{3}$ tris buffer before analysis. The $\mathrm{Gd}(\mathrm{II})$ lines at $376.84 \mathrm{~nm}$ and $409.86 \mathrm{~nm}$ were used for quantification, and each sample was measured three times.

In vitro dissolution test. In vitro dissolution tests were conducted using a mini paddle dissolution apparatus (PTWS model, Pharma Test). Approximately $100 \mathrm{mg}$ of 
Gd(DTPA) / indomethacin loaded fibers were placed in $150 \mathrm{~mL}$ of $0.1 \mathrm{~N} \mathrm{HCl}$ and were transferred to $150 \mathrm{~mL}$ of phosphate buffered saline (PBS; $\mathrm{pH} 7.4) 2 \mathrm{~h}$ later. The medium was kept at $37 \pm 1{ }^{\circ} \mathrm{C}$ and was stirred at a constant speed of $50 \mathrm{rpm}$ under sink conditions. $5 \mathrm{~mL}$ aliquots were withdrawn from the dissolution medium at predetermined time points, and replaced by $5 \mathrm{~mL}$ of fresh pre-heated medium. The indomethacin concentration in the aliquots was quantified at $\lambda_{\max }=266 \mathrm{~nm}$ using a Jenway 7315 UV/vis spectrophotometer. Gd(III) concentrations were analysed by microwave plasma-atomic emission spectroscopy as detailed above. Each experiment was repeated three times, and results are reported as mean \pm S.D.

Proton NMR relaxivity measurements. The longitudinal $\left(T_{1} ; 20\right.$ data points) and transverse relaxation times $\left(T_{2} ; 400\right.$ data points) of water protons were recorded on a Minispec mq20 relaxometer (20 MHz, 0.47 T, Bruker Corporation) at $37{ }^{\circ} \mathrm{C}$, using inversion recovery and CPMG pulse sequences, respectively. Solutions of the fibers in tris buffer with $0.5,0.75$ and $1 \mathrm{mM} \mathrm{Gd}(\mathrm{III})$ concentrations were loaded in 10 mm-diameter NMR tubes and warmed to $37{ }^{\circ} \mathrm{C}$ in a water bath prior to measurement. Each sample was measured three times. Relaxivities were calculated on the basis of a two-point calibration (fibers and no fibers) using the equation $1 / T_{1 / 2}$ $=r_{1 / 2} \times[G d]$.

\section{Results and discussion}

\section{Fiber morphology and structure}

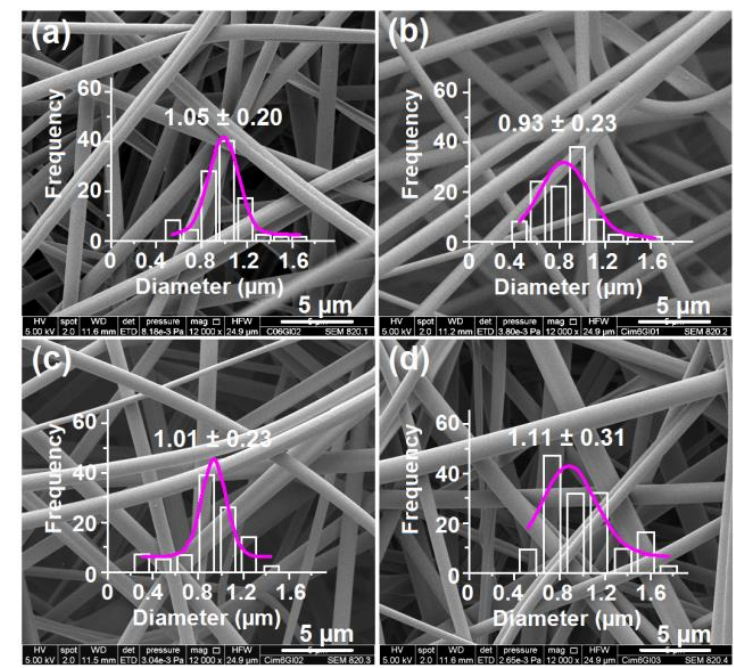

Figure 2. SEM images of the core-shell fibers and their diameter distributions: (a) F1, (b) F2, (c) F3 and (d) F4.

Figure 2 shows the SEM images of the four fiber samples. All have cylindrical shapes, linear morphologies, smooth surfaces and relatively uniform diameter distributions. The average diameter of the core-shell fibers with PEO $1 \mathrm{M}$ as the core increased slightly from $0.93 \pm 0.23 \mu \mathrm{m}(\mathrm{F} 2)$ to $1.11 \pm 0.31 \mu \mathrm{m}$ (F4) as the total content of 
indomethacin and Gd(DTPA) increased from $16.6 \% \mathrm{w} / \mathrm{w}$ in $\mathrm{F} 2$ (8.3\% indomethacin and $8.3 \% \mathrm{Gd}(\mathrm{DTPA}))$ to $37.6 \%$ (18.8\% indomethacin and $18.8 \% \mathrm{Gd}(\mathrm{DTPA}))$ for F4, as can be seen in Table 2 and Figure $2 \mathrm{~b}$ to $2 \mathrm{~d}$. Similar results have previously been reported for monolithic drug-loaded ES100 fibers fabricated using a single fluid electrospinning process. ${ }^{31}$ The average diameter of $\mathrm{F} 1$ is $1.05 \pm 0.20 \mu \mathrm{m}$ (Table 2 and Figure 2a). No particles can be seen on the surfaces of any of the fibers, suggesting no separation of indomethacin or Gd(DTPA) during the electrospinning process.

Table 2. Key data from SEM and TEM on the core-shell fibers.

\begin{tabular}{ccccc}
\hline Fibers & Morphology & $\begin{array}{c}\text { Diameter } \\
(\mu \mathrm{m})\end{array}$ & $\begin{array}{c}\text { Shell thickness } \\
(\mathrm{nm})\end{array}$ & $\begin{array}{c}\text { Core thickness } \\
(\mathrm{nm})\end{array}$ \\
\hline F1 & linear & $1.05 \pm 0.20$ & 160 & 566 \\
\hline F2 & linear & $0.93 \pm 0.23$ & 218 & 277 \\
F3 & linear & $1.01 \pm 0.23$ & 198 & 615 \\
F4 & linear & $1.11 \pm 0.31$ & 228 & 779 \\
\hline
\end{tabular}

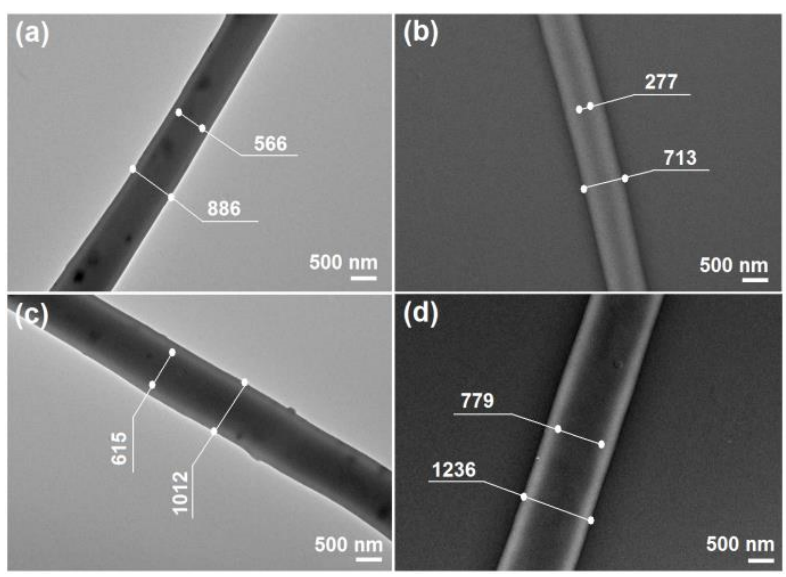

Figure 3. TEM images of the fibers: (a) F1, (b) F2, (c) F3 and (d) F4.

TEM images of the four fibers are given in Figure 3. The core-shell morphology is evident in all cases although no clear-cut boundaries can be discerned between their outer shells and inner cores. The estimated values of the core and shell thicknesses of these fibers are shown in Figure 3 and also summarized in Table 2. In some images, there appear to be several nanoparticles in the cores of the fibers (Figure 3a and c), suggesting some amount of solid phase separation happened during electrospinning. 


\section{Physical form of the components and their compatibility}
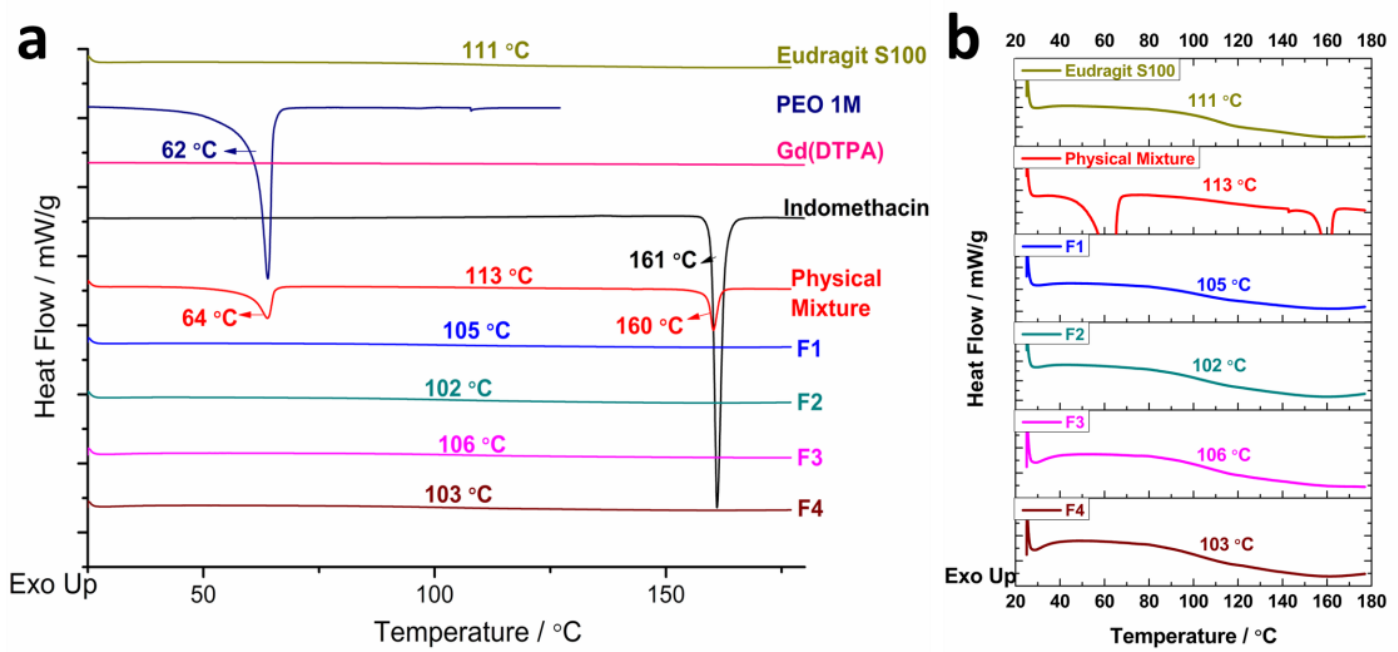

Figure 4. (a) DSC thermograms of the raw materials, a physical mixture, and fibers F1, F2, F3 and F4; (b) Enlargements exhibiting the glass transitions of Eudragit S100, a physical mixture, and fibers F1, F2, F3 and F4.

DSC thermograms are presented in Figure 4. Indomethacin is a crystalline material, as demonstrated by the presence of a sharp endothermic melting peak at $161{ }^{\circ} \mathrm{C}$ in its DSC trace. ${ }^{26}$ PEO $1 \mathrm{M}$ shows an onset melting point at $62{ }^{\circ} \mathrm{C}$, while ES100 displays no melting events, but a glass transition at around $111^{\circ} \mathrm{C}$. This is because the former is a semi-crystalline polymer while the latter is amorphous. The Gd(DTPA) thermogram does not exhibit any melting events, again because it is amorphous. For the physical mixture, there are three phase transitions. The two sharp peaks at $64{ }^{\circ} \mathrm{C}$ and $160{ }^{\circ} \mathrm{C}$ correspond to the onset melting points of PEO and indomethacin respectively, while the glass transition temperature at $113^{\circ} \mathrm{C}$ is attributable to the presence of ES100. No fusion events are detectable in the DSC thermograms of any of the fibers, suggesting that both indomethacin and Gd(DTPA) are present in the fibers in an amorphous state. The $T_{g}$ of Eudragit can be seen to be reduced from that of the raw material in the fibers, as a result of the plasticising influence of the two active ingredients. 


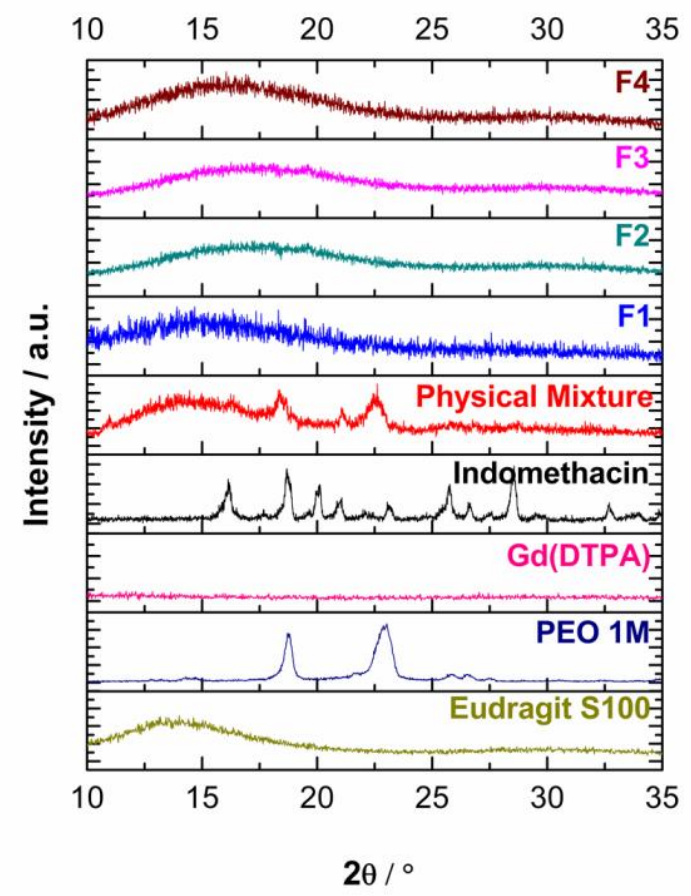

Figure 5. XRD patterns of the raw materials, a physical mixture, and fibers F1, F2, F3 and F4.

XRD patterns are depicted in Figure 5 . The pattern of raw ES100 shows only a broad halo, consistent with the DSC data and proving that the material is amorphous. The PEO $1 \mathrm{M}$ powder exhibits two broad reflections at around $2 \theta=19^{\circ}$ and $2 \theta=23^{\circ}$ since $P E O$ is semi-crystalline. No Bragg reflections are observed in the $X$-ray diffraction pattern of Gd(DTPA), while for indomethacin multiple reflections are present. These results concur with the DSC, demonstrating Gd(DTPA) to be amorphous and indomethacin crystalline. The XRD pattern of a physical mixture shows characteristic reflections corresponding to raw indomethacin and PEO. In contrast, the patterns for the fibers are devoid of any diffraction features, showing the components all to be present in the amorphous physical form. This is in agreement with the DSC results. 

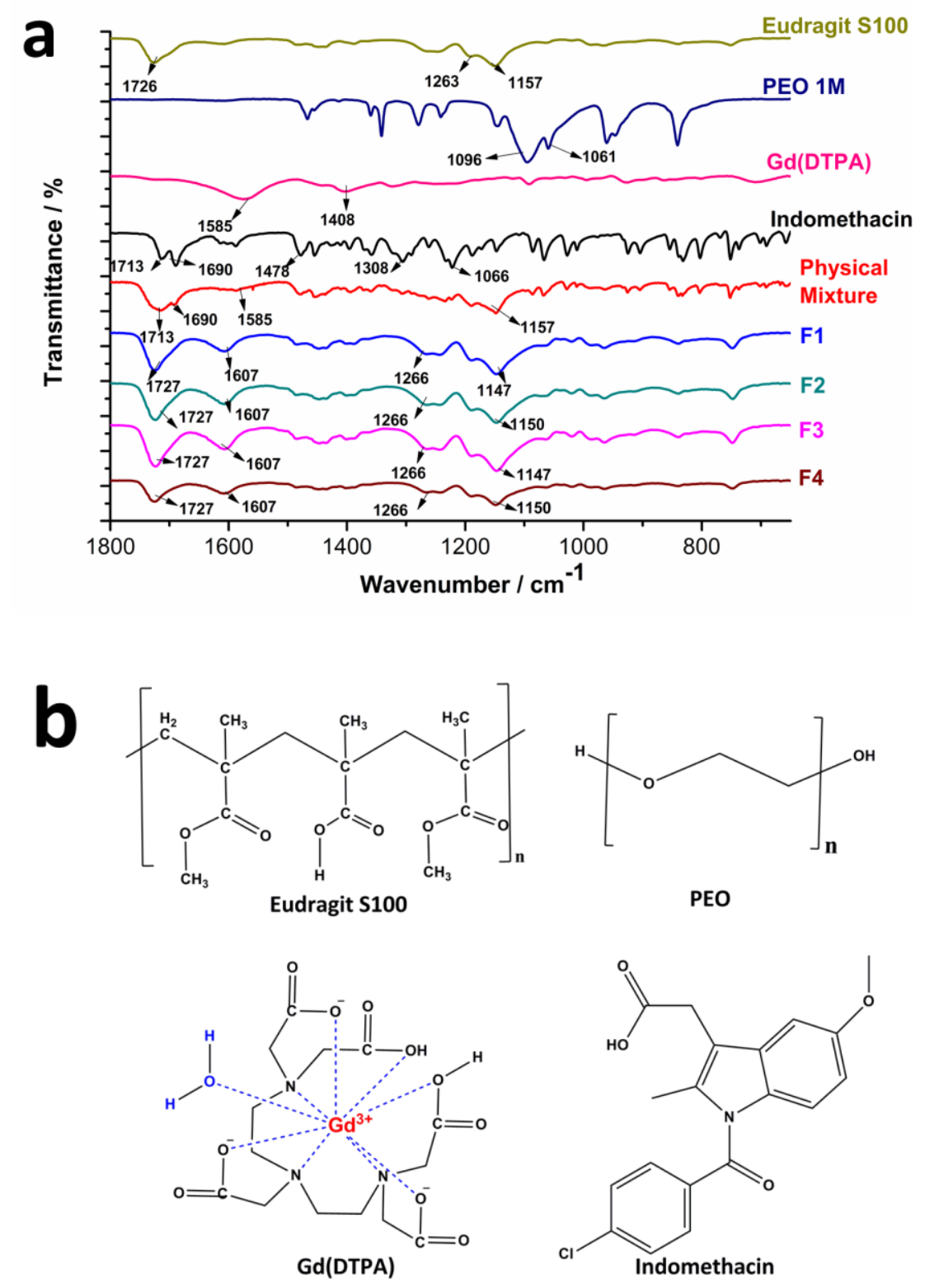

Figure 6. (a) FTIR spectra of the raw materials, a physical mixture, and fibers F1, F2, F3 and F4; (b) Chemical structures of the raw materials.

To evaluate the component compatibility, FTIR spectroscopy was used to analyze the samples (see Figure 6a). In the spectrum of indomethacin, the characteristic peaks at $1713 \mathrm{~cm}^{-1}$ and $1690 \mathrm{~cm}^{-1}$ are associated with aliphatic and benzoyl carbonyl vibration stretching respectively. Other absorbance peaks are visible at $1478(\mathrm{C}=\mathrm{C}$ of aromatic rings), 1308 (C-O of acidic group), 1270-1200 (=C-O of ether group) and $1066 \mathrm{~cm}^{-1}$ (C-Cl). ${ }^{32}$ ES100 shows a characteristic peak at $1726 \mathrm{~cm}^{-1}$ corresponding to carbonyl stretching, with other absorbances present at 1263 and $1157 \mathrm{~cm}^{-1}$ and corresponding to C-O-C stretching vibrations. The characteristic absorption peaks at $1585 \mathrm{~cm}^{-1}$ and $1408 \mathrm{~cm}^{-1}$ in the spectrum of Gd(DTPA) are associated with asymmetric and symmetric $\mathrm{COO}$ stretching vibrations. 
For the physical mixture, the characteristic peaks at 1713 and $1290 \mathrm{~cm}^{-1}$ for indomethacin, $1585 \mathrm{~cm}^{-1}$ for Gd(DTPA) and $1151 \mathrm{~cm}^{-1}$ for ES100 can be observed, but the peaks for PEO are masked by the other three materials. The peak positions of the physical mixture are unchanged from the raw materials, indicating that few interactions occur between the components when they are simply mixed. In comparison with the physical mixture, the characteristic peaks of Gd(DTPA) (1585 $\left.\mathrm{cm}^{-1}\right)$ and indomethacin $\left(1690,1713 \mathrm{~cm}^{-1}\right)$ cannot be resolved in the spectra of the fibers. Almost all the peaks in the fingerprint region of indomethacin have shifted, decreased in intensity, or disappeared in the fibers' spectra. These phenomena suggest that secondary interactions such as hydrogen bonding and hydrophobic interactions occur between the polymer matrix and the loaded active ingredients. By interacting with the polymer, recrystallization of the functional components is retarded.

\section{Leaching studies}

The leaching of free $\mathrm{Gd}(\mathrm{III})$ ions from the fibers could lead to toxicity, because Gd(III) has high affinity for $\mathrm{Ca}$ (II) binding sites. This causes interference with $\mathrm{Ca}$ (II) channels and causes $\mathrm{Gd}(\mathrm{III})$ to be deposited in the liver and bone. ${ }^{33,34}$ To investigate the possibility that free $\mathrm{Gd}(\mathrm{III})$ may leach from the fibers, the composite materials were incubated with arsenazo III $(0.05 \mathrm{mM})$ at $37^{\circ} \mathrm{C}$ in a $\mathrm{pH} 7.4$ tris buffer. The absorbance band of the $\mathrm{Gd}(\mathrm{III})$-arsenazo III complex at $654 \mathrm{~nm}$ was then investigated. Tris buffer and $\mathrm{GdCl}_{3}$ incubated with arsenazo III were used as negative and positive controls. The absorbance spectra are shown in Figure 7.

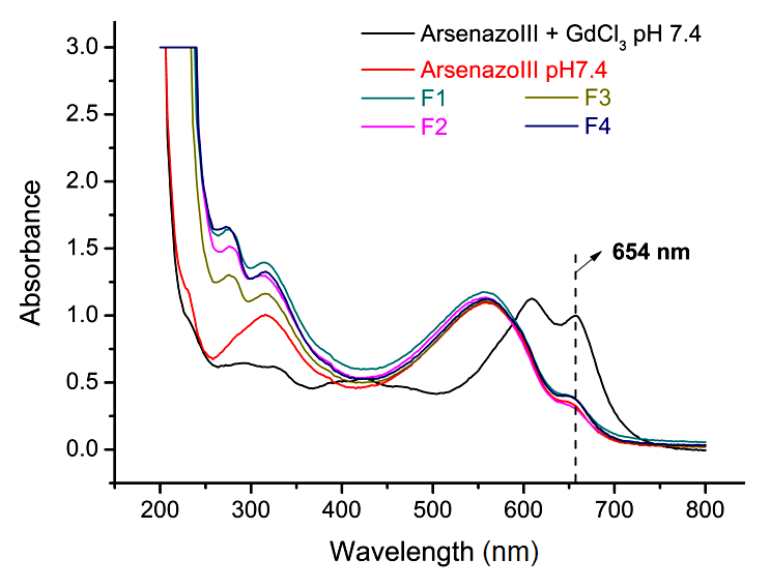

Figure 7. UV absorption spectra of samples F1, F2, F3 and F4 (Gd(III) concentrations: $0.025,0.030$, 0.034 , and $0.038 \mathrm{mM}$ respectively) incubated with arsenazo III. An aqueous $0.076 \mathrm{mM} \mathrm{GdCl}$ solution acted as the positive control.

The positive and negative controls have absorbance values of 0.991 and 0.339 respectively at $654 \mathrm{~nm}$, while the absorbance of the dissolved fibers is very close to that of the negative control. For the low loading fibers F2, no $\mathrm{Gd}$ (III) could be detected in solution with an observed absorbance value of 0.317 . As the content of 
Gd(DTPA) increases (F3 and F4), the intensity of absorbance at $654 \mathrm{~nm}$ increases slightly from 0.385 to 0.394 , indicating that after complete dissolution of the fibers less than $6 \%$ of the Gd incorporated was leached as the uncomplexed Gd(III) ion.

Overall, these results show that there is no significant leaching of free $\mathrm{Gd}$ (III) ions from the fibers - if free ions were present in solution they would complex with the arsenazo-III leading to increased absorbance at $654 \mathrm{~nm}$, while $\mathrm{Gd}$ (III) complexed in Gd(DTPA) cannot bind with the arsenazo ligand and hence there is no additional absorbance at this wavelength.

\section{${ }^{1} \mathrm{H}$ Nuclear magnetic resonance}

The chemical integrity of Gd(DTPA) can be proved by ${ }^{1} \mathrm{H}$ NMR using the analogous La(DTPA) species as a model. ${ }^{1} \mathrm{H}$ NMR spectra are provided in Figure S1. Comparing the NMR spectrum of the dissolved fibers with that of raw indomethacin shows that the chemical structure of indomethacin is intact both after being mixed physically with PEO or after incorporation into PEO monolithic fibers, consistent with reported findings from the literature. ${ }^{35}$ In addition, La(DTPA) also does not seem to be degraded after electrospinning. It still displays multiplets in the range of $1.0-2.0$ ppm because of ligand coordination to the La(III) ion. Therefore, it can be confirmed that the complex structure remains intact after electrospinning, and thus the Gd(DTPA) fibers are expected to be potent as contrast agents.

\section{In vitro drug release}

To mimic the conditions of the human gastrointestinal tract, drug release from the core-shell fibers was first carried out in an acidic solution $(0.1 \mathrm{~N} \mathrm{HCl}$, simulated gastric fluid) for 2 hours and subsequently in a PBS buffer $(\mathrm{pH} 7.4$, simulated intestinal fluid). The amount of indomethacin released from the fibers was measured at $266 \mathrm{~nm}$ by UV spectroscopy. A pre-determined calibration curve was used to determine drug concentration:

$$
A=0.0491 C+0.0044(R=0.9999)
$$

Where $\mathrm{C}$ is the indomethacin concentration $(\mathrm{mg} / \mathrm{L})$ and $\mathrm{A}$ is the absorbance value at $266 \mathrm{~nm}$ (linear range: $0.156-20 \mathrm{mg} / \mathrm{L}$ ).

The in vitro release profiles are shown in Figure 8. 


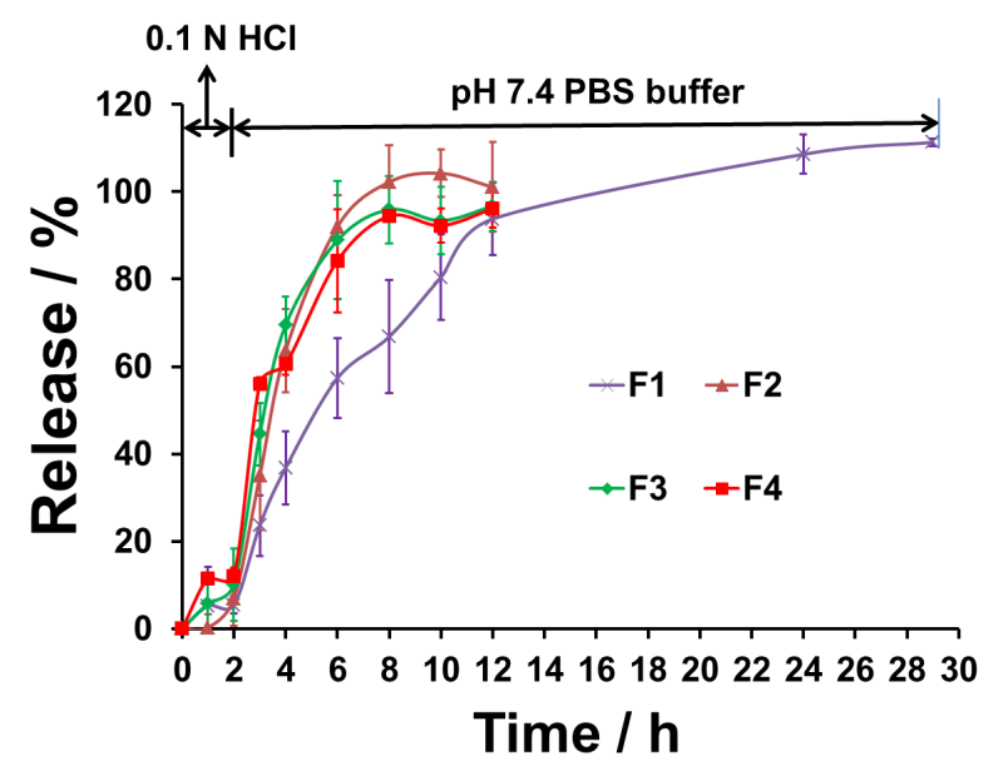

Figure 8. In vitro drug release profiles.

In $0.1 \mathrm{~N} \mathrm{HCl}$, no more than $10 \%$ of indomethacin was released from the composite fibers after $2 \mathrm{~h}$. This is because ES100 is insoluble under these $\mathrm{pH}$ conditions. After

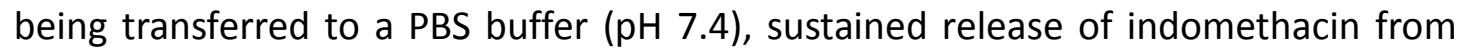
the fibers was observed until $100 \%$ release was reached. The mechanism of indomethacin release was analyzed using the Peppas equation ${ }^{36}$ :

$$
Q=\mathrm{k} t^{\mathrm{n}}
$$

where $Q$ is the drug release percentage, $t$ is the release time, $\mathrm{k}$ is a rate constant, and $\mathrm{n}$ is an exponent that indicates the drug release mechanism. Regressed equations were determined for the release data at $\mathrm{pH} 7.4(\mathrm{t}=$ the time at $\mathrm{pH} 7.4)$ over the period $t=1-8 \mathrm{~h}$ for $\mathrm{F} 1$ and $t=1-6 \mathrm{~h}$ for $\mathrm{F} 2$ to $F 4$, and found to be $Q_{1}=$ $24.15 \mathrm{t}_{1}{ }^{0.587}\left(\mathrm{R}_{1}{ }^{2}=0.996\right) ; \mathrm{Q}_{2}=37.81 \mathrm{t}_{2}{ }^{0.602}\left(\mathrm{R}_{2}{ }^{2}=0.962\right) ; \mathrm{Q}_{3}=47.37 \mathrm{t}_{3}{ }^{0.428}\left(\mathrm{R}_{3}{ }^{2}=0.954\right)$ and $\mathrm{Q}_{4}=53.37 \mathrm{t}_{4}{ }^{0.311}\left(\mathrm{R}_{4}{ }^{2}=0.941\right)$, respectively. The release exponent values are $0.587,0.602,0.428$ and 0.311 . The release exponents for the fibers F1 and F2 are larger than 0.45 but smaller than 1.0, suggesting that the drug was freed into solution through a combined mechanism of polymer erosion and drug diffusion. ${ }^{37}$ However, fibers F3 and F4 had a release exponent smaller than 0.45 , suggesting a typical Fickian diffusion mechanism is operational here.

The amount of Gd(DTPA) released from the fibers could not easily be quantified as a function of time because the concentrations released were very close to the detection limit of the MP-AES instrument. The cumulative amount of complex released from $150 \mathrm{mg}$ of F1 - F4 was quantified, however, and found to be in the range of 2.78 to $7.12 \mu \mathrm{mol}$ (see Table S1). Clinically used preparations of Magnevist, use typically 7.5 to $10 \mu \mathrm{mol}$ of Gd(DTPA) for colorectal lesion detection. ${ }^{38}$ Thus, $160-$ $405 \mathrm{mg}$ of the fibers would provide sufficient $\mathrm{Gd}(\mathrm{III})$ complex for effective imaging. 


\section{Proton relaxivities}

The longitudinal and transverse relaxivities of $\operatorname{Gd}(D T P A)$ and the fibers after dissolution in tris buffer are listed in Table 3. The relaxivities were measured by recording the longitudinal and transverse relaxation rates and the normalized concentration of contrast agent or metal ion (M).

Table 3. Proton relaxivities recorded after dissolution in a tris buffer. Results are reported as mean $\pm S D, n=3$.

\begin{tabular}{cccccc}
\hline Sample & {$[\mathrm{Gd}](\mathbf{m M})$} & $\boldsymbol{T}_{\mathbf{1}}(\mathrm{ms})$ & $\boldsymbol{T}_{\mathbf{2}}(\mathrm{ms})$ & $\boldsymbol{r}_{\mathbf{1}}\left(\mathrm{s}^{-1} \mathrm{mM}^{-1}\right)$ & $\boldsymbol{r}_{\mathbf{2}}\left(\mathrm{s}^{-1} \mathrm{mM}^{-1}\right)$ \\
\hline $\begin{array}{c}\text { Gd(DTPA) in } \\
\text { water }\end{array}$ & 1.00 & $226.20 \pm 1.91$ & $209.46 \pm 2.48$ & $4.42 \pm 0.04$ & $4.77 \pm 0.06$ \\
\hline $\begin{array}{c}\text { Gd(DTPA) in tris } \\
\text { buffer }\end{array}$ & 1.00 & $228.65 \pm 0.49$ & $206.06 \pm 1.78$ & $4.37 \pm 0.01$ & $4.85 \pm 0.04$ \\
\hline $\begin{array}{c}\text { Gd(DTPA)+ } \\
\quad \text { PEO }^{\mathrm{a}}\end{array}$ & 1.00 & $225.85 \pm 0.07$ & $202.83 \pm 2.01$ & $4.43 \pm 0.00$ & $4.93 \pm 0.05$ \\
\hline $\begin{array}{c}\text { Gd(DTPA)+PEO } \\
\text { +Eudragit }\end{array}$ & 1.00 & $143.40 \pm 0.95$ & $121.96 \pm 0.60$ & $6.97 \pm 0.05$ & $8.20 \pm 0.04$ \\
\hline $\begin{array}{c}\text { F1 } \\
\text { F2 }\end{array}$ & 1.24 & $160.13 \pm 0.76$ & $97.37 \pm 1.12$ & $5.03 \pm 0.02$ & $8.28 \pm 0.10$ \\
F3 & 0.48 & $268.50 \pm 2.12$ & $139.30 \pm 2.40$ & $7.76 \pm 0.06$ & $14.96 \pm 0.26$ \\
F4 & 0.79 & $125.00 \pm 3.00$ & $86.19 \pm 3.12$ & $10.13 \pm 0.24$ & $14.69 \pm 0.53$ \\
\hline
\end{tabular}

${ }^{a}$ physical mixtures.

Tris buffer has little effect on the relaxivity of Gd(DTPA), and the $r_{1}$ and $r_{2}$ values are very close to those observed in water. The slight increase in relaxivities observed with a physical mixture of ES100, PEO and Gd(DTPA) is likely to be a result of the tris bridging between ES100/PEO and Gd(DTPA) through hydrogen bonding and electrostatic interactions, resulting in slower rotational motion. ${ }^{39}$ Consequently, all the composite fibers display increased longitudinal relaxivities from 5.03 to 10.13 $\mathrm{s}^{-1} \mathrm{mM}^{-1}$ and transverse relaxivities from 8.28 to $14.96 \mathrm{~s}^{-1} \mathrm{mM}^{-1}$. The ratio of $r_{2} / r_{1}$ for the coaxial materials dissolved in tris buffer ranges from 1.45 - 1.93 [cf. 1.11 for Gd(DTPA)]. Contrast agents with small $r_{2} / r_{1}$ values are found to be efficient as $T_{1} \mathrm{MRI}$ contrast agents. ${ }^{40}$ Similar values of $r_{2} / r_{1}(1.56-1.85)$ were reported for $\mathrm{Gd}(\mathrm{III})$ ions incorporated into mesoporous silica nanoparticles. ${ }^{41}$ These data demonstrate that the formulation prepared in this work should be potent as MRI contrast agents.

To investigate the possible effect of indomethacin on the relaxation properties, it is helpful to consider these systems in comparison with a control set of Eudragit S100/PEO fibers loaded with only Gd(DTPA) prepared in a previous study. ${ }^{29}$ In comparison with the relaxivities of fibers loaded with Gd(DTPA) only (Tables S2 and S3), those of Gd(DTPA)/indomethacin fibers were found to be somewhat lower (e.g. $\mathrm{F} 3$ has $r_{1}=10.13 \mathrm{~s}^{-1} \mathrm{mM}^{-1}$ and $r_{2}=14.69 \mathrm{~s}^{-1} \mathrm{mM}^{-1}$, while the indomethacin-free analogue $\mathrm{F}^{\prime}$ has $r_{1}=12.29 \mathrm{~s}^{-1} \mathrm{mM}^{-1}$ and $r_{2}=18.68 \mathrm{~s}^{-1} \mathrm{mM}^{-1}$ ). This could possibly be due to changes 
in the accessibility of water molecules to the $\mathrm{Gd}(\mathrm{III})$ centre when indomethacin is present. ${ }^{3,42}$ However, in general the presence of indomethacin has little influence on the relaxivities. The co-encapsulation of Gd(DTPA) and indomethacin in electrospun core-shell fibers is hence a promising route for simultaneous colonic MRI and drug delivery.

\section{Conclusions}

Core-shell fibers comprising a shell of Eudragit S100 and polyethylene oxide cores loaded with both Gd(DTPA) and indomethacin were successfully prepared using coaxial electrospinning. The characterizing data showed the fibers to be uniform and cylindrical in morphology, with distinct shell and core compartments and containing an amorphous dispersion of active ingredients. The indomethacin release profiles into gastrointestinal-like media showed little release at $\mathrm{pH} 1$ and sustained release over $12-29 \mathrm{~h}$ at $\mathrm{pH}$ 7.4. The proton relaxivities for Gd(DTPA) released from the fibers in tris buffer increased $\left(r_{1}=5.03-10.13 \mathrm{~s}^{-1} \mathrm{mM}^{-1} ; r_{2}=8.28-14.96 \mathrm{~s}^{-1} \mathrm{mM}^{-1}\right)$ compared with the pure Gd(DTPA) complex $\left(r_{1}=4.37 \mathrm{~s}^{-1} \mathrm{mM}^{-1}\right.$ and $\left.r_{2}=4.85 \mathrm{~s}^{-1} \mathrm{mM}^{-1}\right)$. These novel systems offer a new platform for delivering therapeutic and contrast agents simultaneously.

\section{Supporting information}

Details of the Gd(DTPA) loadings of the fibers, $r_{1}$ and $r_{2}$ values of fibers containing Gd(DTPA) without indomethacin, NMR data for La(DTPA) systems. This material is available free of charge via the Internet at http://pubs.acs.org.

\section{Acknowledgements}

This work was supported by the China NSFC/UK Royal Society cost share international exchanges scheme (No. 51411130128/IE131748) and the National Science Foundation of China (No. 51373101). CFGCG thanks the Portuguese Foundation for Science and Technology for grant UID/QUI/00313/2013, and the FEDER-European Regional Development Fund for funding through the COMPETE Programme (Operational Programme for Competitiveness; grant PEst-OE/QUI/UI0313/2014).

\section{References}

(1) Bhojani, M. S.; Van Dort, M.; Rehemtulla, A.; Ross, B. D. Targeted imaging and therapy of brain cancer using theranostic nanoparticles. Mol. Pharm. 2010, 7, 1921-1929.

(2) Pene, F.; Courtine, E.; Cariou, A.; Mira, J.-P. Toward theragnostics. Crit. Care Med. 2009, 37, S50-S58. 
(3) Liu, Y. J.; Zhang, N. Gadolinium loaded nanoparticles in theranostic magnetic resonance imaging. Biomater. 2012, 33, 5363-5375.

(4) Lammers, T.; Kiessling, F.; Hennink, W. E.; Storm, G. Nanotheranostics and image-guided drug delivery: current concepts and future directions. Mol. Pharm. 2010, 7 , 1899-1912.

(5) Wang, L.; Xing, H.; Zhang, S.; Ren, Q.; Pan, L.; Zhang, K.; Bu, W.; Zheng, X.; Zhou, L.; Peng, W. A Gd-doped Mg-Al-LDH/Au nanocomposite for CT/MR bimodal imagings and simultaneous drug delivery. Biomater. 2013, 34, 3390-3401.

(6) Liao, Z.; Wang, H.; Wang, X.; Zhao, P.; Wang, S.; Su, W.; Chang, J. Multifunctional Nanoparticles vomposed of a poly(DL-lactide-coglycolide) core and a paramagnetic liposome shell for simultaneous magnetic resonance imaging and targeted therapeutics. Adv. Funct. Mater. 2011, 21, 1179-1186.

(7) Sridhar, R.; Lakshminarayanan, R.; Madhaiyan, K.; Barathi, V. A.; Lim, K. H. C.; Ramakrishna, S. Electrosprayed nanoparticles and electrospun nanofibers based on natural materials: applications in tissue regeneration, drug delivery and pharmaceuticals. Chem. Soc. Rev. 2015, 44, 790-814.

(8) Luo, C. J.; Stoyanov, S. D.; Stride, E.; Pelan, E.; Edirisinghe, M. Electrospinning versus fibre production methods: from specifics to technological convergence. Chem. Soc. Rev. 2012, 41, 4708-4735.

(9) Huang, Z.-M.; Zhang, Y. Z.; Kotaki, M.; Ramakrishna, S. A review on polymer nanofibers by electrospinning and their applications in nanocomposites. Compos. Sci. Technol. 2003, 63, 2223-2253.

(10) Boros, E.; Gale, E. M.; Caravan, P. MR imaging probes: design and applications. Dalton Trans. 2015, 44, 4804-4818.

(11) Goh, Y.-F.; Shakir, I.; Hussain, R. Electrospun fibers for tissue engineering, drug delivery, and wound dressing. J. Mater. Sci. 2013, 48, 3027-3054.

(12) Yin, D.; Yang, Y.; Cai, H.; Wang, F.; Peng, D.; He, L. Gambogic acid-loaded electrosprayed particles for site-specific treatment of hepatocellular carcinoma. Mol. Pharm. 2014, 11, 4107-4117.

(13) Oh, B.; Lee, C. H. Advanced cardiovascular stent coated with nanofiber. Mol. Pharm. 2013, 10, 4432-4442.

(14) Yang, Y.; Xia, T.; Chen, F.; Wei, W.; Liu, C.; He, S.; Li, X. Electrospun fibers with plasmid bFGF polyplex loadings promote skin wound healing in diabetic rats. Mol. Pharm. 2011, 9, 48-58.

(15) Yu, D.-G.; White, K.; Chatterton, N.; Li, Y.; Li, L.; Wang, X. Structural lipid nanoparticles self-assembled from electrospun core-shell polymeric nanocomposites. RSC Adv. 2015, 5, 9462-9466.

(16) Khansari, S.; Duzyer, S.; Sinha-Ray, S.; Hockenberger, A.; Yarin, A.; Pourdeyhimi, B. Two-stage desorption-controlled release of fluorescent dye and vitamin from solution-blown and electrospun nanofiber mats containing porogens. Mol. Pharm. 2013, 10, 4509-4526.

(17) Puhl, S.; Li, L.; Meinel, L.; Germershaus, O. Controlled protein delivery from electrospun non-wovens: novel combination of protein crystals and a biodegradable release matrix. Mol. Pharm. 2014, 11, 2372-2380.

(18) Chen, G.; Xu, Y.; Yu, D.-G.; Zhang, D. F.; Chatterton, N. P.; White, K. N. 
Structure-tunable Janus fibers fabricated using spinnerets with varying port angles. Chem. Commun. 2015, 51, (22), 4623-4626.

(19) Lopez, F. L.; Shearman, G. C.; Gaisford, S.; Williams, G. R. Amorphous formulations of indomethacin and griseofulvin prepared by electrospinning. Mol. Pharm. 2014, 11, 4327-4338.

(20) Yu, D.-G.; Williams, G. R.; Wang, X.; Liu, X.-K.; Li, H.-L.; Bligh, S. W. A. Dual drug release nanocomposites prepared using a combination of electrospraying and electrospinning. RSC Adv. 2013, 3, 4652-4658.

(21) Yu, D.-G.; Li, X.-Y.; Wang, X.; Yang, J.-H.; Annie Bligh, S. W.; Williams, G. R. Nanofibers fabricated using triaxial electrospinning as zero order drug delivery systems. ACS Appl. Mater. Interfaces 2015, 7, 18891-18897.

(22) Yu, D.-G.; Li, X.-Y.; Wang, X.; Chian, W.; Liao, Y.-Z.; Li, Y. Zero-order drug release cellulose acetate nanofibers prepared using coaxial electrospinning. Cellulose 2013, 20, 379-389.

(23) Li, C.; Wang, Z.-H.; Yu, D.-G.; Williams, G. R. Tunable biphasic drug release from ethyl cellulose nanofibers fabricated using a modified coaxial electrospinning process. Nanoscale Res. Lett. 2014, 9, 1-10.

(24) Yan, J.; Wu, Y.-H.; Yu, D.-G.; Williams, G. R.; Huang, S.-M.; Tao, W.; Sun, J.-Y. Electrospun acid-base pair solid dispersions of quercetin. RSC Adv. 2014, 4, 58265-58271.

(25) Moghe, A.; Gupta, B. Co-axial electrospinning for nanofiber structures: Preparation and applications. Polym. Rev. 2008, 48, 353-377.

(26) Rasekh, M.; Karavasili, C.; Soong, Y. L.; Bouropoulos, N.; Morris, M.; Armitage, D.; Li, X.; Fatouros, D. G.; Ahmad, Z. Electrospun PVP-indomethacin constituents for transdermal dressings and drug delivery devices. Int. J. Pharm. 2014, 473, 95-104.

(27) McConnell, E. L.; Short, M. D.; Basit, A. W. An in vivo comparison of intestinal pH and bacteria as physiological trigger mechanisms for colonic targeting in man. J. Control. Release 2008, 130, 154-160.

(28) Apicella, A.; Cappello, B.; Del Nobile, M. A.; La Rotonda, M. I.; Mensitieri, G.; Nicolais, L. Poly (ethylene oxide)(PEO) and different molecular weight PEO blends monolithic devices for drug release. Biomater. 1993, 14, 83-90.

(29) Jin, M.; Yu, D. G.; Wang, X.; Geraldes, C. F. G. C.; Williams, G. R.; Bligh, S. W. A. Electrospun contrast agent-loaded fibers for colon-targeted MRI. Adv. Healthcare Mater. 2016, 8, 977-985.

(30) Weinmann, H. J.; Brasch, R. C.; Press, W. R.; Wesbey, G. E. Characteristics of gadolinium-DTPA complex: a potential NMR contrast agent. Am. J. Roentgenol. 1984, 142, 619-624.

(31) Shen, X.; Yu, D.; Zhu, L.; Branford-White, C.; White, K.; Chatterton, N. P. Electrospun diclofenac sodium loaded Eudragit (R) L 100-55 nanofibers for colon-targeted drug delivery. Int. J. Pharm. 2011, 408, 200-207.

(32) Zhang, G.-C.; Lin, H.-L.; Lin, S.-Y. Thermal analysis and FTIR spectral curve-fitting investigation of formation mechanism and stability of indomethacin-saccharin cocrystals via solid-state grinding process. J. Pharm. Biomed. Anal. 2012, 66, 162-169.

(33) Caravan, P.; Ellison, J. J.; McMurry, T. J.; Lauffer, R. B. Gadolinium(III) chelates as MRI contrast agents: Structure, dynamics, and applications. Chem. Rev. 1999, 99, 2293-2352. 
(34) Aime, S.; Caravan, P. Biodistribution of Gadolinium-Based Contrast Agents, Including Gadolinium Deposition. J. Magn. Reson. Imaging 2009, 30, 1259-1267.

(35) Taepaiboon, P.; Rungsardthong, U.; Supaphol, P. Drug-loaded electrospun mats of poly(vinyl alcohol) fibres and their release characteristics of four model drugs. Nanotechnol. 2006, 17, 2317-2329.

(36) Peppas, N. A. Analysis of Fickian and Non-fickian Drug Release from Polymers. Pharm. Acta Helv. 1985, 60, 110-111.

(37) Ritger, P. L.; Peppas, N. A. A simple equation for description of solute release I. Fickian and non-Fickian release from non-swellable devices in the form of slabs, spheres, cylinders or discs. J. Control. Release 1987, 5, 23-36.

(38) Pappalardo, G.; Polettini, E.; Frattaroli, F. M.; Casciani, E.; D'Orta, C.; D'Amato, M.; Gualdi, G. F. Magnetic resonance colonography versus conventional colonoscopy for the detection of colonic endoluminal lesions. Gastroenterology 2000, 119, 300-304.

(39) Cataldo, F.; Da Ros, T.: Medicinal chemistry and pharmacological potential of fullerenes and carbon nanotubes; Springer Science \& Business Media, 2008; Vol. 1. pp. 164.

(40) Na, H. B.; Hyeon, T. Nanostructured T1 MRI contrast agents. J. Mater. Chem. 2009, 19, 6267-6273.

(41) Guillet-Nicolas, R.; Bridot, J.-L.; Seo, Y.; Fortin, M.-A.; Kleitz, F. Enhanced relaxometric properties of MRI "positive" contrast agents confined in three-dimensional cubic mesoporous silica nanoparticles. Adv. Funct. Mater. 2011, 21, 4653-4662.

(42) Na, K.; Lee, S. A.; Jung, S. H.; Shin, B. C. Gadolinium-based cancer therapeutic liposomes for chemotherapeutics and diagnostics. Colloids Surf., B 2011, 84, 82-87. 